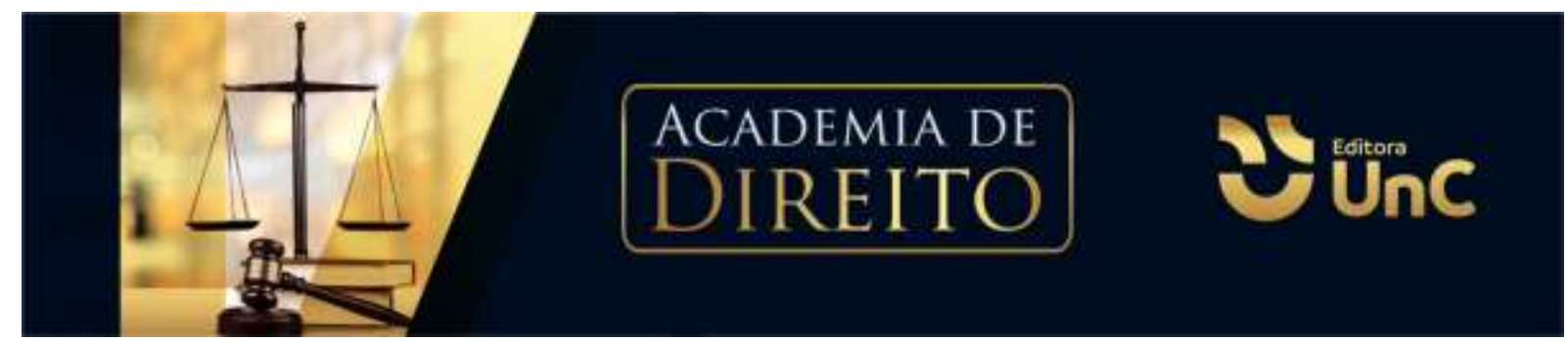

\title{
A CONSTITUCIONALIDADE DA DELAÇÃO PREMIADA REALIZADA PELO DELEGADO DE POLICIA
}

\section{THE CONSTITUTIONALITY OF THE PREMIUM DELATION CARRIED OUT BY THE POLICE COMMISSIONER}

\author{
Alexon Vilarino ${ }^{1}$ \\ Alan Pinheiro de Paula²
}

\begin{abstract}
RESUMO
A delação premiada é considerada uma técnica de investigação por meio de confissão e prestação de informações verídicas para o esclarecimento de delitos. Este trabalho tem como objeto a constitucionalidade e legitimidade de o delegado de polícia, nos casos previstos em lei, aplicar esta ferramenta de investigação criminal. O presente estudo deu-se pelo método dedutiva por meio de pesquisas bibliográficas, doutrina e jurisprudência realizadas no Brasil. Objetiva-se pesquisar por casos utilizando-se da teoria dos jogos por meio de suas regras, táticas e estratégicas. Busca-se refletir sobre os requisitos, etapas e procedimentos no jogo da delação premiada. Busca-se também observar os limites da teoria dos jogos no tratamento das provas e dos direitos do delatado. Conclui-se que o delegado de polícia fundamenta a investigação criminal, conforme entendimento constitucional, assim como, possui legitimidade para realizar a delação premiada.
\end{abstract}

Palavras-Chave: Constitucionalidade. Delação Premiada. Delegado de Polícia. Teoria dos Jogos.

\section{ABSTRACT}

The winning complaint is considered an investigation technique through confession and provision of truthful information for the clarification of crimes. This work has as its object the constitutionality and legitimacy of the police chief, in the cases provided for by law, to apply this criminal investigation tool. The present study was carried out by the deductive method through bibliographic research, doctrine and jurisprudence carried out in Brazil. The objective is to search for cases using game theory through its rules, tactics and strategies. It seeks to reflect on the requirements, steps and procedures in the game of the winning sentence. It also seeks to observe the limits of

\footnotetext{
${ }^{1}$ Acadêmico de Graduação em Direito, Universidade do Contestado (UnC). Campus Mafra. Santa Catarina. Brasil. E-mail: alexon.vilarino@aluno.unc.br

${ }^{2}$ Mestre em Ciência Jurídica pela Universidade do Vale do Itajaí (Univali). Itajaí. Santa Catarina. Brasil, Docente e Pesquisador da Universidade do Contestado. Campus Mafra. Santa Catarina. Brasil. E-mail: alanpinheirodepaula@gmail.com
} 
game theory in the treatment of evidence and the rights of the whistleblower.It is concluded that the police chief justifies the criminal investigation, in accordance with the constitutional understanding, as well as having the legitimacy to carry out the winning complaint.

Keywords: Constitutionality. State's Evidende. Police Commissioner. Game Theory.

\section{INTRODUÇÃO}

A delação premiada é utilizada no âmbito da investigação de organizações criminosas que, por meio de delatores, tem por objetivo buscar informações precisas e indícios probatórios de veracidade dos fatos delitivos.

Entretanto, a delação premiada no Brasil é novidade no sistema processual penal. Excepcionalmente, o modelo delacional ainda é motivo de impasses e contradição e vem sendo adotado por Delegados de Polícia e membros Ministério Público.

Dessa maneira, novos mecanismos foram aprimorados a partir da Lei 12.850/13, denominada Lei de Organização Criminosa, que dispõe sobre investigação criminal e a obtenção de prova na persecução penal. Dentre alguns objetivos está a tendência pela Justiça Negocial, inspirada na experiência americana, europeia e latino-americana. Ademais, o sistema de colaboração estatal passou a ter características de negociação jurídica entre acusação, defesa e a mediação do Estado - Juiz.

Qual é a importância de o delegado de polícia realizar a deleção premiada?

A delação traz requisitos e regras, possibilitando o delator de fazer a escolha voluntária de colaborar tanto com a acusação. Além disso, esse protagonismo do delator pode ser decisivo na persuasão do juiz.

Na delação premiada, a aplicação do jogo negocial pode ser vista quase uma incerteza. As técnicas de dissimulação são comportamentos aprimorados pelos jogadores. Na lógica, o objetivo é jogar com o oponente psicologicamente, buscando a verdade e identificando fatores potenciais para cada procedimento negocial no seu respectivo contexto.

O presente trabalho se justifica em exposição da teoria dos jogos aplicada pelo Delegado de Polícia em que o investigado visa a saber os benefícios por meio de 
recompensa (redução da pena). Ademais, a autoridade policial colabora com a persecução criminal respeitados os princípios da proporcionalidade e razoabilidade.

Para esse escopo, foi utilizado o método dedutivo a partir do uso da dedução para obtenção de uma conclusão acerca da premissa objeto desse artigo, a partir de pesquisa bibliográfica, doutrina e jurisprudência.

\section{A DELAÇÃO PREMIADA NO BRASIL E CARACTERÍSTICAS}

No Brasil, um instituto muito comentado e discutido no sistema judiciário brasileiro é a delação premiada, a qual se tornou ferramenta legal na aplicação de crimes de combate à corrupção e a perseguição da verdade oculta por meio de procedimento investigatórios.

A delação busca a colaboração em troca de prêmio ou benefício ao acusado (penas menores, reversão de regime e, dependo do contexto, o perdão judicial). Para isso, as informações prestadas e gravadas necessitam esclarecer fatos apurados úteis para a investigação. De modo a garantir o direito do delator, o depoimento será na presença de defensor/advogado e, caso queira, o investigado poderá pedir sigilo de seu depoimento e proteção a integridade física assegurada pelo Estado.

A legislação, em se tratando da delação premiada, traz sua aplicação em fase processual do recebimento da denúncia até o trânsito em julgado, abrangendo ainda a execução penal. Cabe destacar que, na seara investigativa, a contribuição do delator pode fornecer subsídios importantes na gravidade dos fatos e reflexos sociais.

Corrobora com a temática Rogério Sanches Cunha:

\footnotetext{
É necessário que o delator demonstre interesse em efetivamente colaborar com as autoridades, não ocultando a sua participação ou de qualquer outro fato que seja de interesse da investigação. Do contrário, caracterizado que o delator está mentindo ou omitindo, não será cabível a delação e ainda, poderá esta, se já homologada, ser rescindida (CUNHA, 2013, p.36).
}

A delação é o instituto que apresenta a oportunidade de o investigado contar sobre os fatos e colaborar com o Estado na eficácia da investigação para posterior ação penal. "A lei estabelece três requisitos para a colaboração premiada: voluntariedade, eficácia da colaboração; e circunstâncias subjetivas e objetivas favoráveis" (MENDONÇA, 2013, p.13). 
A má regulamentação do procedimento da delação gera impasses no conteúdo, forma e compreensão dos procedimentos deste instituto. Ganhou força após a Operação Lava Jato e se aperfeiçoou após as homologações de acordo por força e efeitos de suas cláusulas.

Conforme as palavras de Rodrigo Chemin:

A ausência de delatores torna a tarefa investigativa complexa, demorada e cara. O atalho proporcionado é valioso, e deve ser considerado no contexto de organizações criminosas autênticas, já que as limitações estatais são preenchidas pela colaboração interessada de insiders (CHEMIN, 2017, p.34).

No Brasil, o Delegado de Polícia e os membros do Ministério Público utilizam técnicas de negociação para elucidação de determinados crimes. Ademais, a capacidade de compreender o investigado torna a colaboração mais eficiente em estratégias de reunir meios de prova na investigação, assim como os defensores elaboram teses mais robustas e fundamentadas.

O modelo normativo da delação no Brasil, apresenta adaptações e é insuficiente para consolidar a responsabilização penal.

"Somos favoráveis à delação premiada, embora reconheçamos que há certa ambiguidade e ausência (parcial) de regras claras sobre o modo de produção desse modelo negocial" (BÊRNI, 2004, p. 10).

De acordo com Antônio Henrique Graciano Suxberger (2015, p. 649-665):

\begin{abstract}
Parece pouco realístico defender que os meios de obtenção de prova descritos no Código de Processo Penal brasileiro são suficientes para o enfrentamento da 'criminalidade organizada'. A tendência mundial para a sofisticação dos mecanismos de obtenção de prova desembarcou no Brasil gerando certo histerismo por parte do senso comum teórico, dada a necessidade de novas categorias e de ruptura com as práticas investigatórias vintage, a saber, as de sempre. Novas criminalizações, com maior organização e transcendência ao território nacional, exigiram a adoção de novas modalidades de investigação.
\end{abstract}

A adoção de uma justiça negociada no sistema processual brasileiro, têm elementos na fase extrajudicial. Destarte, o possível culpado pode aceitar o benefício a fim de reduzir a quantidade da pena ou possível perdão judicial dos processos criminais. 


\section{O JOGO DA DELAÇÃO PREMIADA}

O jogo da delação premiada se dá fora do ambiente jurisdicional e, eventual controle, somente ocorrerá em caso de ação penal futura. Nesse sentido, o ambiente em que a culpa é apurada é pré-processual. Essa responsabilidade transfere-se para investigação, que passa a ser o procedimento para delação.

De acordo com o Supremo Tribunal Federal:

[...]. O Poder Judiciário é convocado ao final dos atos negociais apenas para aferir os requisitos legais de existência e validade, com a indispensável homologação no julgamento do HC 127.483/PR. Ademais, conforme informativo $n^{\circ} 870$, referente aos dias 19 a 30 de junho de 2017, 'no ato de homologação da colaboração premiada, não cabe ao magistrado, de forma antecipada e extemporânea, tecer juízo de valor sobre o conteúdo das cláusulas avençadas, exceto nos casos de flagrante ofensa ao ordenamento jurídico vigente. Se assim agir, estará interferindo indevidamente na atuação dos órgãos de investigação, porque a celebração do acordo de colaboração premiada não trata de medida submetida à reserva de jurisdição' (BRASIL, 2017, p.5).

Na delação, o déficit normativo deixa o jogo mais complexo. Para que se possa ter sucesso, é preciso conhecer o "jogador adversário" e apresentar as regras que se irá aplicar e desconsiderar. Nesse sentido, o juiz poderá recusar homologação à proposta que não atender aos requisitos legais, ou adequá-la se preciso for. Essa postura imparcial é importante para a garantia das regras justas.

Nesse contexto, Vinícius Gomes de Vasconcellos (2015, p.117) elenca requisitos de validade da colaboração:

\footnotetext{
1) consentimento do réu a partir de vontade livre, esclarecida e consciente; 2) necessidade de lastro probatório para a confirmação da confissão; 3) imprescindibilidade do acompanhamento de advogado em todos os atos; 4) postura passiva do julgador (proibido de participar das negociações); 5) possibilidade de retratação; 6) vedação da utilização da declaração de culpa em caso de insucesso da negociação.
}

O jogo da negociação na etapa negocial, selado entre Delegado de Polícia ou Ministério Público e investigado, consiste na confiança e da boa-fé objetiva, sobre comportamentos futuros, a saber, a coerência com o comportamento posterior, principalmente nas fases sucessivas até o acordo de delação. 
"O Estado não pode praticar ilegalidades, omitir informações desfavoráveis, valer-se de métodos não autorizados em lei, potencializar inescrupulosamente elementos probatórios" (RAMOS, 2006, p.24).

Cabe destacar que as nulidades ou abusos podem se dar em relação ao procedimento ou mesmo às provas obtidas. Estas duas possibilidades devem ser analisadas de maneira diversa, para se entender e compreender a importância do fair play.

A ideia de jogo como algo no comportamento negocial não é tarefa exclusiva individual, depende de comportamentos de terceiros, interação estratégica entre jogadores/julgadores no contexto (tempo - espaço) da tomada de decisão. Não se trata de jogos de azar com loteria e roleta, que independe de qualidades dos jogadores, mas sim de capacidade técnica, tática o que submete o sujeito à negociação.

A forma como se joga, através do domínio de táticas e estratégias, pode ser interpretada como uma ameaça, oferta, abertura e até mesmo cooperação entre os jogadores. "A protagonista dos jogos negociais é sempre uma ação humana, nos limites de sua racionalidade, e daí a importância da teoria dos jogos" (ROBLES, 2011, p.12).

O jogo tem sido alvo de críticas por conta de subjetividades, seja pela falta de ética ou do "jogo sujo", no entanto, isso não significa que de posse das informações, possa se manipular as pessoas. A manipulação rompe com jogo limpo ou flair play; desorganiza o jogo limpo, até mesmo descumpre preceitos processuais, o que veda o processo penal brasileiro.

Note-se, que o momento de negociação das cláusulas do contrato sofre influências das táticas elencadas pela teoria dos jogos (blefes, truques, ameaças, trunfos) podendo alterar informações prestadas pelo jogador-defensor. "O ganho do jogador acusador é igual à perda do jogador defensor e vice-versa, já que o conjunto a ser dividido na delação não é o mesmo, trabalha-se com a liberdade e feitos penais" (DAVIS, 1973, p. 53).

O dispositivo da delação/colaboração trouxe possibilidade de acordos, cooperação para fins de aplicação da pena. O meio utilizado para administrar o jogo são as informações disponíveis, tanto à qualidade, quantidade no decorrer da negociação. 
Como explica Morton David Davis (1973, p.18):

A metáfora da Teoria dos Jogos como instrumento (formal) de compreensão do procedimento de delação parte da pressuposição de que o resultado não depende exclusivamente da performance de um dos jogadores, mas decorre da interação humana, das tática e estratégias dominantes/dominadas utilizadas no limite temporal do procedimento, mediante a capacidade de convencimento cooperativo.

A teoria dos jogos traz o campo matemático, o poder de mostrar o mecanismo no processo penal sob a perspectiva da interação humana. É possível cooperação e, neste sentido, a teoria reconhece as dificuldades práticas dos delatores e a obtenção de ganhos passa a depender da performance dos jogadores e da capacidade de convencimento (ROBLES, 2011).

Nesse aspecto, o investigador procura otimizar as decisões e ações a fim de garantir a melhor jogada na partida negocial. A estratégia dominante, nas mãos do Estado, opera com informações privilegiadas no jogo da investigação e constitui elementos cruciais na interação (ROBLES, 2011).

A ideia é compreender que a delação é um mercado de compra e venda (de provas) e que os colaboradores/delatores são os vendedores da informação. Nem sempre a proposta é apresentada ao investigado ou acusado, deixando-o sem alternativas negociais no processo criminal. "Não há direito subjetivo do investigado à oferta de colaboração premiada" (ANSELMO, 2016 p.44).

Assim quanto às condutas do comportamento dos indivíduos, cabe analisar a dos interesses das organizações. Quando se trata de instituições, estas pautam suas ações de acordo com macroestratégias dinamizadas pelas direções (ANSELMO, 2016). Para isso, por meio das táticas técnico-negociais, adota-se diligências específicas e os caminhos de escolha são voltados à fonte e coerência do argumento, com o auxílio de equipe multidisciplinar para maior credibilidade na negociação e restrições aos negociadores.

Os jogos negociais e investigatórios se alternam constantemente, todavia, a maioria dos jogadores são amadores, sabem as regras processuais de cor e salteado, mas não compreendem a efetividade e eficiência à interação negocial. A qualidade e quantidade de informações aderidas ao procedimento negocial deve ter preocupação e cautela (LOPES, 2005). 
O problema de arriscar todas as fichas em uma única estratégia inflexível é que se algo der errado, perde-se tudo. "As recompensas podem estar contaminadas por um ódio que não se satisfaz com a vitória, porque deseja o impossível. Para alguns acusadores/defensores, em nome da vitória, não há limites" (LOPES, 2005, p.44).

Embora o negociador-investigador queira informações qualificadas, a questão é saber seu limite. Toda informação tem um preço e este é o desafio, a busca por informação capaz de municiar o negociador para articular argumentos vencedores, a carta na manga é um trunfo. Logo, improvável a obtenção da informação completa, o desconhecido é desconhecido por definição, exige-se que o delator sustente as versões em processos penais futuros.

A cooperação tende a ser mais efetiva com jogadores públicos do que privados, dada a recompensa possível, francamente vinculada à carga de trabalho. "O que se tem é uma mercadoria por um preço. Para melhor compreendermos o modelo, precisaremos mensurar o intricado jogo de cooperação ou não (traição)" (MARINHO, 2011, p. 34).

O comportamento negocial depende do perfil teórico e pessoal de cada jogador, além do contexto do jogo e de sua dinâmica. O resultado depende da sucessão de subjogos e da informação-prova válida capazes de cooptar cognitivamente o adversário (DAVIS, 1973).

O jogo negocial é baseado na incerteza e o detalhe modifica o resultado. As ferramentas da dissimulação fazem parte do auto interesse dos jogadores tais como conduta reprovável. Na lógica, a ideia é desarmar a oponente psicológica, midiática e materialmente, tornando-o impotente às possibilidades de resistência (DAVIS, 1973).

No meio policial, a coleta de informações em relação a organizações criminosas violentas (facções ou milícias) é difícil por motivo do pacto de silêncio entre os envolvidos (SANTOS, 2013).

A colaboração com a Justiça envolve não somente o direito de liberdade dos negociadores, mas a vida dos familiares dos investigados, aqui os jogos são fatais.

\section{A REPRESSÃO À ORGANIZAÇÃO CRIMINOSA (LEI N. 12.850/13)}

A colaboração premiada prevista pela Lei n. ${ }^{\circ} 12.850 / 13$ veio substituir a metodologia adotada pela antiga lei de crime organizado. Essa ferramenta possibilita 
a análise da pena pelo Estado juiz, por meio de colaboração e confissão de autoria (FONTES, 2017). Já a defesa poderia se sentir pressionada em aceitar o acordo para evitar o processo e o risco de condenação. Por parte de alguns juízes pode um estimular à aceitação de propostas a fim diminuir processos (LOPES JUNIOR, 2020).

Para Aury Lopes Junior (2020, p.23):

O panorama é ainda mais assustador quando, ao lado da acusação, está um juiz pouco disposto a levar o processo até o final, quiçá mais interessado que o próprio promotor em que aquilo acabe o mais rápido e com menor trabalho possível. Quando as pautas estão cheias e o sistema passa a valorar mais o juiz pela sua produção quantitativa do que pela qualidade das decisões, o processo assume sua face mais nefasta e cruel. Sintoma disso é que, logo após o anúncio do projeto "anticrime", mesmo despondo que qualquer justificativa ou fundamentação, uma pesquisa da AMB (Associação dos Magistrados Brasileiros) apontou que $90 \%$ apoiam a pleabargaining.

Além da delação, ampliou-se o acordo de leniência, que possui o mesmo propósito de delação, com a principal diferença voltada aos crimes de cartel, nos quais a pessoa jurídica será imposta redução da punição (Lei. 10.149, art.35-B). Ainda dentro dessa discussão, a "compliance" abrange um sistema de avaliação de condutas praticadas na atividade empresarial. A lógica é promover a prevenção interna (legal, regulamentar, ética, etc.), tanto em atos da pessoa jurídica, bem como dos agentes vinculados, monitorando as práticas internas, controlando os desvios e responsabilizando possíveis atuações externas (penal, cível e administrativo). (SANTOS,2013).

Corrobora com o assunto Celio Jacinto dos Santos (2013, p. 79):

\begin{abstract}
A investigação criminal complexa conceitua-se a partir da relação com a investigação de organizações criminosas e seus delitos. A complexidade da investigação está associada à dificuldade de acesso aos dados sensíveis ao fenômeno criminal, que são dissimulados em suas variáveis espaciais, temporais e modais.
\end{abstract}

Da mesma forma, a investigação leva em conta a atuação dos envolvidos, com a identificação de referências de ocultações de bens, lavagem de capitais, influências na administração pública e, o mais grave, risco à vida de testemunhas, partícipes e coautores.

Diante da investigação criminal, a descoberta de fatos, a definição racional dos caminhos deve ser adotada no momento da produção de provas cautelares e 
informações. "O uso de novas tecnologias na investigação criminal apresenta uma gama de possibilidades de produção de provas, alterando o panorama estrutural dos órgãos de Polícia Judiciária, promovendo a atualização da atividade policial" (COSTA ANDRADE, 2009, p.131).

O monitoramento de organizações criminosas é uma das ferramentas probatórias e, por conseguinte, apresenta instrumento de acompanhar conduta crimina e evitar provas produzidas via novos recursos sejam invalidades por ausência de regulamentação legal (MACHADO, 2016).

Com o advento da Lei. 12850/13, apresentaram-se novos meios hábeis de informações de partícipes, coautores e autores do crime investigado. Na negociação da culpa mediante colaboração, as sanções poderão ser melhor analisadas pelo Estado Juiz (MACHADO 2016).

De acordo com Stephen Trott (2007), as novidades da lei de organização criminosa trouxeram maior aplicação nas possibilidades de: captação ambiental de sinais eletromagnéticos e ópticos, agente infiltrado e ação controlada, por exemplo. Mesmo assim, não dispensam o princípio da dignidade da pessoa humana, da reserva da vida privada, da intimidade, dentro outros direitos fundamentais que possam ser direta ou indiretamente prejudicados, inclusive em face de terceiros.

A lei. 12850/13 ao elencar e não regulamentar o procedimento e requisitos, deixou lacuna que impede a utilização da gravação ambiental.

Insta visualizar que a adoção da justiça negociada no sistema processual brasileiro confere mais protagonismo ao procedimento investigativo, pois passará por base elementos colhidos em fase extrajudicial. Nesse sentido, cabe salientar que o inocente, poder-se-ia sentir se pressionado a aceitar o acordo com o fim de evitar o processo e a probabilidade de condenação sem indícios de materialidade e de autoria (TROTT, 2007).

De qualquer forma, a aplicação do enquadramento de situações narradas e devidamente documentadas é lógico para o deferimento de cautelares probatórias. Para isso, torna-se indispensável: o dolo do agente ao se associar; a divisão de tarefas, o objetivo econômico e a finalidade de cometer infrações punitivas com penas superiores à 4 (quatro) anos (RODRIGUES, 2010). 
Nesse aspecto, a eventual dificuldade no combate ao crime organizado não pode ser objeto de crítica apenas no uso da delação premiada. Mas sim no completo entendimento do sistema jurídico penal.

\section{A DELAÇÃo PREMIADA APLICADA PELO DELEGADO DE POLÍCIA}

Os protagonistas da cooperação são os jogadores (Delegados de Polícia e/ou Ministério Público, já superada a controvérsia sobre a possibilidade de negociação exclusiva pelo delegado, sem ou com adesão do Ministério Público - ADI 5508) e os jogadores da defesa investigado/acusado, necessariamente, assistido por defensor (COUTINHO, 2018).

A posição do STF é de que o alinhamento dos órgãos estatais pode melhorar o grau de eficiência da atividade negocial. É sabido, especialmente em casos de flagrante após o juízo tomar conhecimento, que se estabeleçam limites nas diligências. Nesse cenário, o instituto da ação controlada nas investigações torna-se necessária e imprescindível no amparo das negociações (COUTINHO, 2018).

O termo de delação tem estrutura de ficção estabelecida pelo delator, uma espécie de versão vendida dos acontecimentos. A narrativa parte de uma linha de pensamento de conforto probatório sobre alvos de recompensa, logo a acusação pode ser facilmente manipulada pelo viés confirmatório. A argumentação opera pela ideia lógica do discurso, com início, meio e fim confortada de provas mínimas e consistentes (COUTINHO, 2018).

Cada vez o jogo da delação exige preparo profissional, capaz de dominar a lógica do processo penal com sentença de mérito e saber contra quem se joga. As recompensas dos delatores investigados, processados e condenados estão direcionados a imediatidade da devolução da liberdade plena (TROTT, 2007).

O critério de manutenção da própria razão de ser da delação, de preservação da razão instituidora, a vantagem que o delatado possa auferir deve estar presente. "O jogo de salvar a própria pele inspira relações e afrouxa laços de confiança. Em caso de naufrágio, todos pegam o primeiro salva-vidas [...]" (TROTT, 2007, p. 48).

Enfrentar grandes organizações, munidas de recursos financeiros, políticos e jurídicos, requer habilidades, os delatores possuem dinheiro para explorar pontos fracos até mesmo de agentes da lei (COUTINHO, 2018). 
Após homologada a delação, o delator muitas vezes viola termos pactuados e com isso surge a teoria do adimplemento substancial (CHUIERI, 2017).

O Superior Tribunal de Justiça no julgamento do Resp. 1.581.505/SC (Min. Antônio Carlos Ferreira) deixou assentado sobre a aplicação da teoria do adimplemento substancial:

\begin{abstract}
A aplicação da Teoria do Adimplemento Substancial exigiria, para a hipótese, o preenchimento dos seguintes requisitos: a) a existência de expectativas legítimas geradas pelo comportamento das partes; b) o pagamento faltante há de ser ínfimo em se considerar o total do negócio; c) deve ser possível a conservação da eficácia do negócio sem prejuízo ao direito do credor de pleitear a quantia devida pelos meios ordinários (BRASIL, 2016, p. $316-$ 321).
\end{abstract}

Para a delação, a tática muda no decorrer do jogo, porque os jogadores estruturam possíveis decisões intervenientes. Avaliam riscos, antecipam as jogadas são considerados agentes racionais dispostos a alcançar a recompensa pretendida. No direito atual à proibição de cartel, de "trust", tendo plena aplicabilidade na colaboração/delação premiada (CHUIERI, 2017).

O contrato de delação não é processo, mas os efeitos deste não deixam de ser equivalentes, visto que o contrato tem peso de acarretar sanções penais. Já a obtenção favorecida pelo processo penal na Justiça Negociada ("plea bargaining") traz os reflexos dos custos do sistema penal e do mercado judicial (COOTER, 2010).

Conforme Robert Cooter (2010, p.48):

\begin{abstract}
A premissa de que quem pratica crime se expõe ao risco da punição e quanto maior o preço a pagar, menos incentivos terá, parte de um sujeito racional teórico e abstrato, incompatível com o lugar das práticas criminalizadas. Mas, é o modelo de raciocínio que preside boa parte do movimento recrudescedor, cujos efeitos declarados, todavia, são reduzidos.
\end{abstract}

No direito penal, a discussão está no âmbito das condutas e o preço da punição, ou seja, a sociedade acredita que a severidade da resposta estatal e a probabilidade de ser preso e punido resulta no modelo de culpa imposta pelo Estado (FONTES, 2017).

Posteriormente, a assimetria de informações (o delator não sabe tudo o que a acusação sabe), estabelece a tendência de sonegar e proteger informações relevantes. O sigilo protege o valor da informação e momento da revelação deve ser 
planejado. Aqui cabe destacar, que o delegado possui obrigação de meio da fase inicial de procedimento administrativos (COOTER, 2010).

Em suma, o delator pode se comprometer com o depoimento, durante 0 processo de delação, em geral gravado, mas não pode ter o benefício condicionado à condenação dos delatados, todavia isso depende da atribuição de culpa por outras autoridades públicas (ROSA, 2019).

Por fim, entender a dimensão do jogo negocial pressupõe saber reconhecer e aprender com erro. A transparência e publicidade dos termos da delação depois homologados implica diminuição de assimetria de informações sobre o que estava sendo negociado e as obrigações recíprocas. Com a demanda de transparência e furos de reportagem, cada vez mais a negociações são vazadas antes mesmo de homologadas e circulam em sites, fica evidente os segredos das informações do processo (ROSA, 2019).

$\mathrm{Na}$ negociação, o Estado apresenta as cartas em face da probabilidade de condenação possíveis penas e implicações. No jogo da delação os jogadores apostam que terão frente jogadores-julgadores a mão probatória capaz de ganhar o jogo (ROSA, 2019).

Por fim, o Estado precisa garantir o princípio da segurança jurídica, presente na Constituição Federal de 1988, garantindo dosagem e controle no uso de seu pode diante de infração cuja existência não tenha prévio conhecimento, quiçá o delator.

Dentre as características da delação, encontra-se o conhecimento mais oculto da infração penal cometida. $O$ instrumento necessita seguir requisitos para que se possa ser válida a investigação, tanto na sua constitucionalidade como legalidade.

Com o advento da Constituição Federal de 1988, destaca-se o sigilo das informações apresentadas pelo delator, bem como de sua identidade, respeitados os direitos e garantias fundamentais.

Veja-se:

Art. $5^{\circ}$ Todos são iguais perante a lei, sem distinção de qualquer natureza, garantindo-se aos brasileiros e aos estrangeiros residentes no País a inviolabilidade do direito à vida, à liberdade, à igualdade, à segurança e à propriedade, nos termos seguintes: XII - é inviolável o sigilo da correspondência e das comunicações telegráficas, de dados e das comunicações telefônicas, salvo, no último caso, por ordem judicial, nas hipóteses e na forma que a lei estabelecer para fins de investigação criminal ou instrução processual penal (BRASIL, 1988). 
A legitimidade na busca de possíveis delitos por meio de diligências, traz à tona a importante figura da autoridade de polícia. O Delegado de Polícia preside a investigação criminal realizada por meio do inquérito policial. Nada mais coerente que este detenha legitimidade para celebrar acordos de colaboração (ANSELMO, 2016).

As investigações possuem características a depender do crime a ser apurado; as ferramentas disponíveis e necessárias resultam celeridade e qualidade no objetivo principal que é descobrir a verdade. A forma de investigação tradicional, clássica, calcada em um processo de recognição de um fato praticado, remontando pedaços de história (CARNELUTTI, 2009).

Em prol da legitimidade de atuação do delegado de polícia na delação premiada, a Consultoria-Geral da União lembrou que a Lei 12.850/2013 foi submetida a amplo debate por representantes da magistratura, do MP, da Defensoria Pública, das Polícias Federal e Civil e do Ministério da Justiça e que não cabe centralizar no Ministério Público todas as atribuições do sistema de persecução criminal (DANTAS, 2020).

Corrobora com o assunto Márcio Adriano Anselmo (2016), o qual sintetiza a necessidade da prevalência do interesse público:

É preciso que haja um entendimento das instituições, porque me parece que é da atuação conjunta, integrada, dos dois órgãos que poderemos ter, nós, sociedade brasileira, melhor eficácia no esclarecimento de crimes (ANSELMO, 2016, p. 123).

As medidas cautelares passíveis de representação direta pelo delegado de polícia ao Poder Judiciário não estão reproduzidas apenas no texto da Lei 12.850/2013, que teve chancelada a sua constitucionalidade pelo Supremo Tribunal Federal. Elas são veiculadas e reforçadas em inúmeros dispositivos legais, por decorrência e desdobramento lógico do julgamento da ADI 5.508, e de uma interpretação sistemática e integradora do ordenamento jurídico constituem o cabedal laboral do delegado de polícia (SILVA, 2020).

Crimes mais complexos, com maior organização e até mesmo com transcendência ao território nacional, necessitaram a adoção de novas modalidades de investigação, verificada competência e circunscrição de cada Delegado de Polícia. A colaboração é uma forma de se obter provas, e cabendo a 
polícia a produção na fase investigatória, nada mais legítimo a autoridade policial representar por cumprimento de finalidade institucional de polícia judiciária.

\section{CONSIDERAÇÕES FINAIS}

Por conseguinte, a delação premiada e cooperação são de fundamental importância na sustentação da persecução penal. É um mecanismo dinâmico e de elucidação dos fatos investigados pelo Estado, mediante concessão de acordo de boa-fé do delator, ou seja, instrumento de obtenção de provas.

No Brasil, a delação trouxe considerações importantes em relação à regra da negociação. O pressuposto do acordo, entretanto, é a confiança nas palavras e a pactuação do cumprimento. A delação premiada como meio de normatividade de ambiente negocial pode ser realizada pelo Delegado de Polícia sem ou com adesão do Ministério Público, conforme entendimento do STF (Supremo Tribunal Federal) em julgamento de ADI 5508.

Em segunda análise, a teoria dos jogos é uma ferramenta formal utilizada no contexto do procedimento negocial por meio da interação humana, táticas e estratégias dominantes cujo resultado se dá mediante a capacidade de convencer por meio cooperativo. A teoria dos jogos presume que o indivíduo visa a benefícios por meio da recompensa (redução da pena, vencer a negociação). A teoria é entendida como jogo, pois as pessoas precisam de estratégia, plano de ação e cada negociação é única dentro do seu contexto. É necessário experiência e talento no jogo do blefe, alguma informação real ou potencial requer postura de confiança, pois a delação não se constitui de prova, e sim instrumento de obtenção de provas capazes de contribuir no desfecho do andamento das investigações.

A partir desse pressuposto, a atuação é democrática e obriga, todavia, a atender aos limites e obrigações de modo a respeitar os direitos fundamentais e a dignidade da pessoa humana. Além disso, cabe destacar a proteção do garantismo penal brasileiro e acima de tudo os princípios constitucionais da ordem social mínima, proporcionalidade e aplicar o instituto para minimizar danos de modo a respeitar os direitos do delator. 
Por fim, a linha tênue do equilíbrio do ilícito e lícito é o que se espera do Poder Judiciário frente à negociação do lado do responsável pela obtenção das informações (delegado e/ou Ministério Público) e da defesa. Afinal, no processo penal brasileiro, a tática é a mesma, saber jogar e/ou negociar. Diante disso, o delegado de polícia é agente público em busca de fatos que embasam a investigação criminal, e que de forma constitucional possui legitimidade para concretizar a delação premiada.

\section{REFERÊNCIAS}

ANSELMO, Márcio Adriano. Colaboração premiada: o novo paradigma do processo penal brasileiro. Rio de Janeiro: M. Mallet, 2016.

BÊRNI, Duilio Á. Teoria dos jogos: jogos de estratégia, estratégia decisória, teoria da decisão. Rio de Janeiro: Editora Reichmann\& Affonso, 2004.

BRASIL, Supremo Tribunal Federal. Habeas - Corpus n. 127.483-PR. Relator: Ministro Edson Fachin. Brasília -DF. 2017. 19 a 30 de junho de 2017, n.870. p.5. Disponível em: http://www.stf.jus.br/arquivo/informativo/documento/ informativo870.htm.

BRASIL, Superior Tribunal de Justiça. Recurso Especial n. 1.581.505-SC. Ministro: Antônio Carlos Ferreira. Brasília -DF.18 de agosto de 2016. p. 316 - 321. Disponível em: https://stj.jusbrasil.com.br/jurisprudencia/862933393/recurso-especial-resp1581505-sc-2015-0288713-7/inteiro-teor-862933403?ref=serp.

CARNELUTTI, Francesco. As misérias do processo penal. São Paulo: Editora Pillares, 2009.

CHEMIN, Rodrigo. Mãos limpas e lava jato: a corrupção se olha no espelho. Porto Alegre: CDG, 2017.

COSTA ANDRADE, Manuel da. Bruscamente no verão passado, a reforma do código de processo penal. Coimbra, 2009.

COUTINHO, Jacinto Nelson de Miranda; LOPES JUNIOR, Aury; ROSA, Alexandre Morais da. Delação premiada no limite: a contravertida Justiça Negocial Made in Brasil. Florianópolis: EModara, 2018.

CHUIERI, Rodrigo Cunha. Adimplemento substancial: pratica contratual e critérios qualitativos. Curitiba: Juruá, 2017.

CUNHA, Rogério Sanches; PINTO, Ronaldo Batista. Crime organizado: comentários à nova lei sobre o crime organizado. Lei $n^{\circ} 12,850 / 2013$. Salvador. Juspodivm, 2013. 
DAVIS, Morton David. Teoria dos jogos: uma introdução não-técnica. São Paulo: Cultrix, 1973.

DANTAS, Tiago Baltazar Ferreira. Acordo de colaboração premiada e o delegado de polícia.na visão do STF. Conteúdo Jurídico, Brasília-DF. Disponível em: https://conteudojuridico.com.br/consulta/Artigos/52083/acordo-de-colaboracaopremiada-e-o-delegado-de-policia-na-visao-do-stf

FONTES, Márcio Schiefler. Novas fronteiras da investigação: o processamento de atos de corrupção e a colaboração premiada. Florianópolis: Empório do Direito,2017.

LOPES JUNIOR, Aury. Direito processual penal. Editora do Direito. 2020.

LOPES, Júlio Aurélio Vianna. A invasão do direito: a expansão jurídica sobre o Estado, o mercado e a moral. Rio de Janeiro: FGV, 2005.

MACHADO, Leonardo Marcondes. O amadorismo na investigação criminal cobra seu preço no jogo processual. Disponível em: https://www.conjur.com.br/2016-jan 26/academia-policia-amadorismo-investigacao-cobra-preco-jogo-processual. Acesso em 9 set. 2020.

MARINHO, Raul. Prática na teoria: aplicações da teoria dos jogos e da evolução aos negociadores. São Paulo: Saraiva, 2011.

MENDONÇA, Andrey Borges De. A Colaboração premiada e a nova Lei do crime organizado (Lei 12.850/2013). Custos legis: a revista do Ministério Público, v. 4. 2013.

RAMOS, João Gualberto Garcez. Curso de processo penal norte-americano. São Paulo: RT, 2006.

ROBLES, Gregorio. As regras do direito e as regras dos jogos: ensaio sobre a teoria analítica do direito. Trad. Pollyana Mayer. São Paulo: Noeses, 2011.

RODRIGUES, Benjamin Silva. Da prova penal. Tomo II. Lisboa: Rei dos Livros, 2010.

ROSA, Alexandre Morais. BERMUDEZ, André Luiz. Para entender a delação premiada pela teoria dos jogos: táticas e estratégias do negócio jurídico, 2019.

SILVA, Márcio Alberto Gomes. Pode o delegado de polícia representar diretamente medidas cautelares ao judiciário, no curso do inquérito policial?. Revista Jus Navigandi, Teresina, a. 17, n. 3396,18 out.2020. Disponível em: https://jus.com.br/artigos/22829. Acesso em:1 set. 2020.

SUXBERGER, Antônio Henrique Graciano. A funcionalização como tendência evolutiva do direito internacional e sua contribuição ao regime legal do banco de identificação de perfil genético. Revista de Direito Internacional, Brasília, v.12, n. 2, 2015, p. 649-665. 
TROTT, Stephen. O uso de um criminoso como testemunha: um problema especial, Trad. Sérgio Fernando Moro. Revista CEJ, Brasília, a. 11, n.37, p. 68-93, abr./jun. 2007.

VASCONCELLOS, Vinicius Gomes de. Barganha e justiça criminal negocial: análise das tendências de expansão dos espaços de consenso no processo penal brasileiro. São Paulo: IBC-CRIM, 2015.

Artigo recebido em: 31/08/2020

Artigo aceito em: 05/11/2020

Artigo publicado em: 28/06/2021 